\title{
EXPLORING VISUAL MANAGEMENT PURPOSES IN CONSTRUCTION PROJECTS
}

\author{
Fernanda M. P. Brandalise', Barbara Pedo ${ }^{2}$, Daniela D. Viana ${ }^{3}$, and Carlos T. \\ Formoso $^{4}$
}

\begin{abstract}
The application of the lean construction principle of increasing process transparency is the main purpose of Visual Management (VM), a strategy for making information clear and accessible. There are other purposes of VM, such as continuous improvement, job facilitation, and simplification. However, the connections among those purposes are not fully explored in the literature, which limits the current conceptual understanding of VM. The aim of this paper is to propose a conceptual map of the VM purposes in construction projects, based on the analysis of three VM practices. This research study is part of a broader ongoing research project which objective is learning and teaching about VM through a serious game that considers different VM aspects. Design Science Research was the methodological approach adopted in this investigation. The main findings of this study are concerned with some connections between different VM purposes. Some of these purposes are specific, while others are more generic. Moreover, a specific purpose may have a different meaning for each practice, so context analysis plays an important role. Finally, different ways of shared understanding by using VM practices have been identified, such as by adhering to standards or by encouraging collaboration.
\end{abstract}

\section{KEYWORDS}

Visual management, purpose, lean construction, learning, teaching.

\section{INTRODUCTION}

Increasing process transparency is the most cited purpose of Visual Management (VM), a strategy for making information clear and accessible (Tezel et al. 2016). In fact, visualization can contribute to information flow management, supporting communication among stakeholders, and increasing accessibility to information, which can support fast decision-making (Lindlöf 2014). Previous research has pointed out that VM purpose is not related only to the observable portion of VM practices, but especially to the "nonvisual work" involved in it (Nicolini 2007).

1 Ph.D. Candidate, School of Engineering, Building Innovation Research Unit (NORIE), Universidade Federal do Rio Grande do Sul (UFRGS), Brazil, +5551999302604, fernandampbrandalise@ gmail.com, orcid.org/0000-0001-5126-4741

2 Ph.D. Candidate, School of Art, Design and Architecture, University of Huddersfield, UK, b.pedo@hud.ac.uk, orcid.org/0000-0002-6520-0981

3 Adjunt Professor, Interdisciplinary Department, Universidade Federal do Rio Grande do Sul (UFRGS), Brazil, danidietz@gmail.com, orcid.org/0000-0001-8958-4708

4 Professor, School of Engineering, Building Innovation Research Unit (NORIE), Universidade Federal do Rio Grande do Sul (UFRGS), Brazil, formoso@ ufrgs.br, orcid.org/0000-0002-4772-3746 
However, there are other purposes of VM, also named in the literature as functions or objectives, such as improving understanding of schedules (Tezel and Aziz 2017) and giving quick information feedback (Tezel et al. 2018; Valente et al. 2019). Dallasega et al. (2018) argue that VM also increases work capacity as it supports information accessibility and availability of real-time data collection and processing. Tezel et al. (2009) also provided a classification of VM purposes, such as job facilitation and simplification.

Tezel et al. (2016), in turn, suggested a systematic application of VM aiming to emphasize its benefits, but those authors pointed out that there is a mismatch between the proposed benefits of VM in the literature and those achieved in practice. That is due to the lack of conceptual clarity and the scattered literature showing an only limited understanding of VM. Besides that, research on VM is a fundamental strategy of lean production (LP) (Mejabi 2003). Tezel et al. (2016) suggest that a generic understanding of the subject is necessary, without confining it only to the production domain.

The aim of this paper is to propose a conceptual map of VM purposes, based on the analysis of three VM practices. This investigation is part of a wider research project under development which objective is learning and teaching about VM through a serious game for improving the conceptual understanding of the subject and its role as a strategy to cope with complexity in construction projects. This game allows several analyses to be carried out. Besides the discussion about purposes, other steps of the game consider different aspects of VM practices such as context understanding, requirements, the role of communication, and the role of collaboration. The artifact presented in this paper is a reflection of discussions on VM purposes that were held in the initial applications of the game. This was selected to be the first conceptual outcome of this investigation, but it is expected that other theoretical contributions might be produced as the development of the game evolves. Moreover, it is expected that future reflection on the set of concepts and practices involved in the game, based on participants' perceptions, will provide a broad understanding of the use of VM in construction projects.

\section{PURPOSES OF VISUAL MANAGEMENT}

The main purpose of VM is to increase process transparency to promote improvements in the production systems and the overall management of organizations (Tezel et al. 2016). $\mathrm{VM}$ is also related to the reduction variability and the elimination of non-value-adding activities (Formoso et al. 2002; Koskela et al. 2018), as well as to continuous improvement (Bernstein 2012; Brady et al. 2018; Eaidgah et al. 2016), other fundamental LP principles (Koskela 2000).

It is also noteworthy that VM enables a faster and more reliable approach of communication compared to traditional alternatives, contributing to the reduction of cycle time and to the reduction of variability, which also explains its intrinsic role in LP (Koskela et al. 2018). Tezel et al. (2009) also pointed out VM purposes of simplifying and unifying information. In fact, VM can mitigate problems related to the management of complex production systems, for example when used to support collaboration in planning and control meetings (Viana et al. 2014). Management by facts (Gunasekaran et al. 1998), discipline by following the right procedures (Hirano 1995), and direct support for other management efforts (safety management, performance measurement, and production management, etc.) can also be classified as VM purposes (Tezel 2011). VM devices can vary in form, level of standardization, and level of collaboration required by the users. On one hand, a simple visual indicator such as a board with the sentence "drink water" may not be effective in changing behavior because people are used to seeing it and 
no longer even think about its message. While, on the other hand, a collaborative planning board facilitates the understanding of each team about tasks to be undertaken and existing constraints, helping to organize the planning process. Therefore, some VM practices can mitigate problems related to system complexity by sharing the right information on time and removing information barriers in the work environment (Valente et al. 2019)

Another VM purpose pointed out in the literature is associated with the increase in workforce motivation (Galsworth 1997), by enabling the participation of many people in decision making (Greif 1991; Klotz et al. 2008). This helps to promote collaboration between team members (Ewenstein and Whyte 2007). Besides that, VM can facilitate work (Tezel et al. 2009), giving autonomy to the employees (Greif 1991), because it creates a sense of shared ownership, and supports on-the-job training (Tezel et al. 2009, 2016). Valente et al. (2019) described specific purposes for different VM practices that, in general, establish a common understanding and support the exchange of information, besides encouraging the joint processing of information. In fact, systematic implementation of VM establishes a visual workplace in which various purposes of VM can be observed (Tezel et al. 2016).

\section{RESEARCH METHOD}

Design Science Research (DSR) was the overall methodological approach adopted in this investigation. This approach consists of the development of artifacts for solving classes of problems (van Aken 2004; Holmström et al. 2009). DSR was adopted due to the prescriptive character of this investigation, as it comprises a dynamic process between problem understanding and solution development through incremental learning cycles (Lukka 2003). However, the research study described in this paper has a descriptive character, as its focus is on understanding the underlying ideas of VM best practices. Similarly to what is undertaken in Evaluation Research, as described by Clarke and Dawson (1999), the outcomes of such a descriptive study can be used for a prescription.

The main source of evidence used in this investigation was participant observation in the application of the VM game, as well as perceptions of students, professionals, and academics about the purpose of VM. Those perceptions were obtained through interactive online workshops among participants, using word clouds diagrams to show and discuss results.

This paper covers part of the outcomes resulting from the application of the game in three opportunities. Three VM practices were selected: "pipe template", "exposed work execution procedure in images and video", and "collaborative planning". Forty-five people were involved in the workshops. All of them had a background in architecture or civil engineering: $13.3 \%$ researchers on VM, 2.2\% Ph.D. students, $20 \%$ master students, $20 \%$ undergraduate students, and $44.4 \%$ practitioners.

Firstly, the research team presented an image of the practice in question explaining a situational concern and its countermeasure. Then, respondents should write their perception of the main purpose of the VM practice presented. An online and interactive presentation software was used to support respondent's answering during the meetings, and the resulting word cloud was presented synchronously on the screen. This means that the first respondents may influence the last ones. Each respondent could write as many terms as they want until the established time limit was reached (an average of 7 minutes), and the word size in the resulting word cloud indicates the frequency that each term was mentioned: the bigger size of the word, the more often it was mentioned. Finally, the researchers and respondents discussed the diagram to refine the understanding of the 
purposes of that VM practice. The presentation of the results right after the voting session enabled a deeper discussion among participants.

The VM practice "pipe template" had its purposes discussed in two online meetings, "exposed work execution procedure in images and video" in three, and "collaborative planning board" in only one. The collected data were transferred to a database. Except for the first meeting to discuss "exposed work execution procedure in images and video", which was carried out in English, all other meetings were in Portuguese. Therefore, subsequently, the terms were translated into English in this database. Then researchers developed a word cloud for each VM practice discussed. All words mentioned for each practice were included in the resulting word cloud.

Finally, an analysis of words was realized: similar ones were grouped into a common term. Then, these final set of terms about the purposes of the three VM practices discussed were connected, forming a conceptual map, the main artifact of this investigation, in which the relationships between VM purposes are made explicit.

\section{RESULTS}

\section{Pipe Template}

In construction projects, there is the need of installing hydraulic pipes in the correct location according to the design. Aiming to assure that, a possible countermeasure is to use a cut rug as a template (Figure 1 (a)). It is especially useful in projects with floor design repetition. By identifying the location where pipes should be installed, it eliminates the need to measure. The use of templates makes it easier and faster to complete the work.

As exposed in that VM practice description, the main purpose pointed out by participants was "standardization" or making a "standard" (36.4\%, 8 out of 22$)$, i.e., the cut rug is a template to be followed as a pattern for pipe installation. The consequence of using it is to reduce the probability of errors by installing pipes in the wrong places. In fact, objectives related to "mistake avoidance", such as "avoid mistakes", "mistake proofing", and "poka-yoke" were the second more remembered by $31.8 \%$ (7 out of 22) of respondents. Other purposes had less mention but were equally related to each other: the lean construction principle of "reduce cycle time" (4.5\%, 1 out of 22) through by "eliminate set-up" $(4.5 \%, 1$ out of 22$)$ would "increase productivity" $(4.5 \%)$ as also result in more "excellence" $(4.5 \%, 1$ out of 22$)$ of the final product. An answering frequency of 22 times resulted in the 11 purposes mentioned in the word cloud of Figure 1 (b).
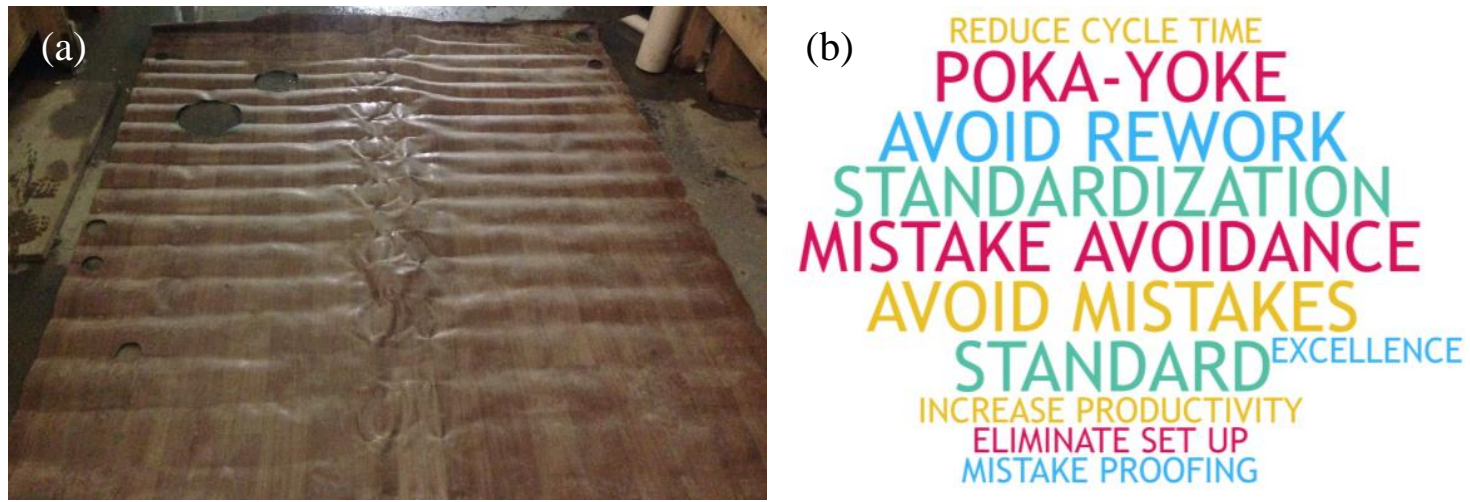

Figure 1: VM practice "pipe template" (a), and its purposes (b) 


\section{ExPosed Work Execution Procedure IN IMAgeS AND Video}

It is expected that workers should learn and be reminded on how to execute some working procedures, which are explained in the training programs. To support that, a possible countermeasure is to provide a board close to the workplace where images illustrate the procedure sequence (Figure 2 (a)). If the worker wants more information, he/she can scan the image with a mobile phone (functioning as a QRcode) and a video will be open, giving him some autonomy for learning.

"Autonomy" (also understood as "self management") and "standardization" (e.g. "delivery of job standard", and "standardize") were the most mentioned purposes for $13.7 \%$ of respondents each ( 7 out of 51 each). It was followed by the purpose of increasing "quality" (5.9\%, 3 out of 51), and giving "visibility" (3.9\%, 2 out of 51$)$, which is strongly related to the lean principle of "increase process transparency" (Koskela 1992) mentioned as "transparency" by $2 \%$ of participants ( 1 out of 51 ). This VM practice also presented a lot of other purposes, which were pointed out by $2 \%$ (1 out of 51) of respondents each one (e.g. "learning", "belonging", and "efficiency"), totaling in 51 replies distributed in the 37 terms observed in Figure 2 (b).
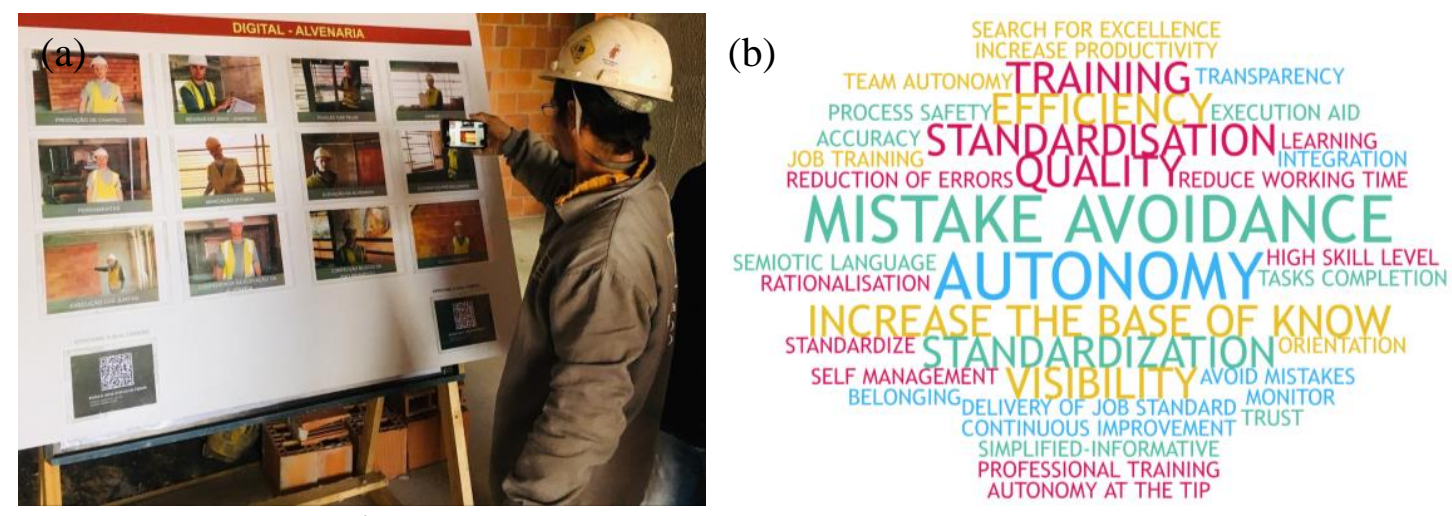

Figure 2: VM practice "exposed work execution procedure in images and video" (a), and its purposes (b)

\section{Collaborative Planning Board}

There is a need to create a shared understanding of scope, key milestones, major constraints, and a logical sequence of work in the design stage. In this way, analogue (Figure 3 (a)) or virtual (Figure 3 (b)) collaborative boards can be used as a countermeasure to support master and phase planning of Last Planner® System (Ballard and Howell 1998; Howell and Ballard 1999). In response to the COVID-19 situation, the digital implementation of this VM practice through virtual meetings has become essential for making design decisions.

In fact, it does not matter where it happens, collaborative planning supported by VM had as most cited purposes the terms "commitment", "engagement", and "integration", with $11.5 \%$ each one ( 3 out of 26 each). These result in "collaboration", as mentioned by $7.7 \%$ of respondents ( 2 out of 26 ). Besides that, though a "share knowledge" (also mentioned by $7.7 \%, 2$ out of 26 , participants), a "common understanding" can be achieved due to the "information unit" encouraged, as argued by $3.8 \%$ ( 1 out of 26 ) of people. All 18 purposes about this VM practice pointed out in a total frequency of 26 answers are summarized in a word cloud (Figure $3(\mathrm{c})$ ). 

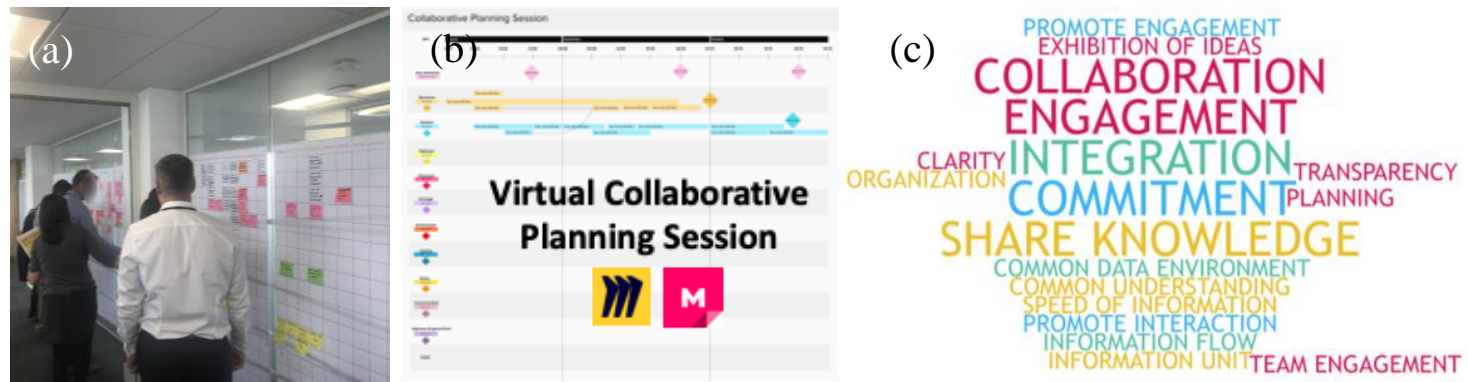

Figure 3: VM practice "collaborative planning board" analogue (a) and virtual (b), and its purposes (c).

\section{DISCUSSION}

The purposes identified by the game participants in word clouds for the three VM practices were analyzed and grouped by similarity. Twenty-four main VM purposes were found. Many of them are strongly related to each other, so the authors developed the following conceptual map (Figure 4).

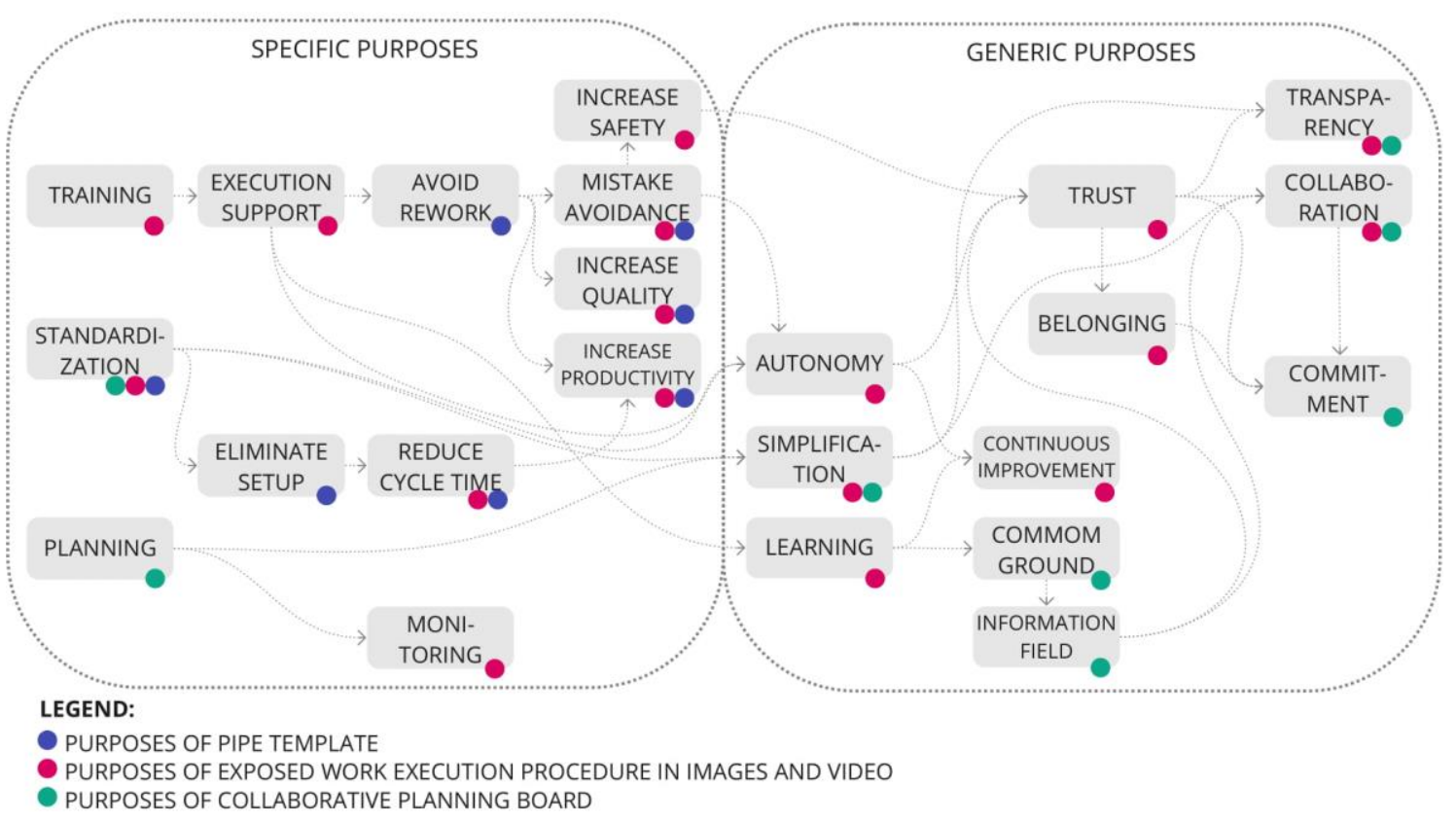

Figure 4: Conceptual map of VM purposes.

The "training" purpose, which was suggested by Tezel et al. (2016), was addressed by the VM practice of exposed work execution procedure. "Training" has a positive impact in "execution support", which can have a positive effect in "avoid rework". The purpose of 'avoiding rework' was addressed by the pipe template VM practice as workers were able to do the task correctly from the first time of execution. Thereby, an "increase of quality" and an "increase of productivity" can be observed, as well as "mistake avoidance", which can "increase safety" and also gives "autonomy" to the employee, as pointed out by Greif (1991). This "autonomy" happens especially due to the "execution support" purpose mentioned by Tezel et al. (2009), as the employee would be capable of doing the task by himself/herself, through "standard" procedures (Hirano 1995).

The "planning" purpose of the collaborative planning practice, in turn, is a way of generating "simplification" (Tezel et al. 2009) enabling people to "collaborate" 
(Ewenstein and Whyte 2007) in the planning process, as it is easy to understand interdependencies between activities. Besides, facilitating "monitoring", as well as the "execution support" results in "learning". This creates a "common ground" and "continuous improvement", another objective of VM already pointed out by literature (Bernstein 2012; Brady et al. 2018; Eaidgah et al. 2016) which is also a consequence of "autonomy" (Greif 1991). If people are aware of their responsibilities, there is room for suggesting some improvements. The "common ground" is related to the unification purpose (Tezel et al. 2009), the common understanding (Valente et al. 2019), and the global management support (Tezel 2011). It allows the creation of an "information field" that together with the "increase safety" gives "trust" to the workers making decisions (Greif 1991; Klotz et al. 2008), besides supporting their "collaboration" (Ewenstein and Whyte 2007).

"Standardization" was the only purpose mentioned for the three VM practices analyzed. As mentioned by Tezel et al. (2016), it helps to simplify ("simplification") the steps of the work and to "eliminate setup", which, in turn, "reduces cycle time" (Koskela et al. 2018), a well-known lean production principle (Koskela 1992) that "increases productivity". It also gives "autonomy" to users resulting in an environment with "transparency". In fact, VM is a strategy for increasing process transparency (Tezel et al. 2016) and it is also proportioned by "trust", strongly related to the "belonging" feeling, the shared ownership (Tezel et al. 2016) that results in the crew's "commitment". Finally, this "commitment" also is a consequence of "collaboration" caused by "trust".

As observed in Figure 4, VM practices can present a range of purposes (Tezel et al. 2016) and they can be related. Some of them are more specific, more objective, and related directly to the practice use, i.e., more related to visual work involved. These purposes are located more to the left, such as "training", "execution support", "planning", and "monitoring". In turn, others are more generic and abstracts, i.e., more related to nonvisual work involved, such as "autonomy", "transparency", "collaboration", and "commitment". Those are located on the right side of Figure 4.

The three practices selected are fairly different in terms of their purposes. For example, although "standardization" was cited as a purpose of the three practices, it has a different meaning in each practice (Figure 5). The pipe template is related to the product standardization, it is focused on the result. The exposed work execution procedure is associated with the process, in which the idea is to make workers perform a task in the same way. The collaborative planning board uses the idea of process standardization differently. It standardizes the routines and the way people should interact, and also the VM interface. The interesting paradox of this practice is that standardizing the process of planning creates a means for changing the previously established plan and collaboratively affecting the final product.

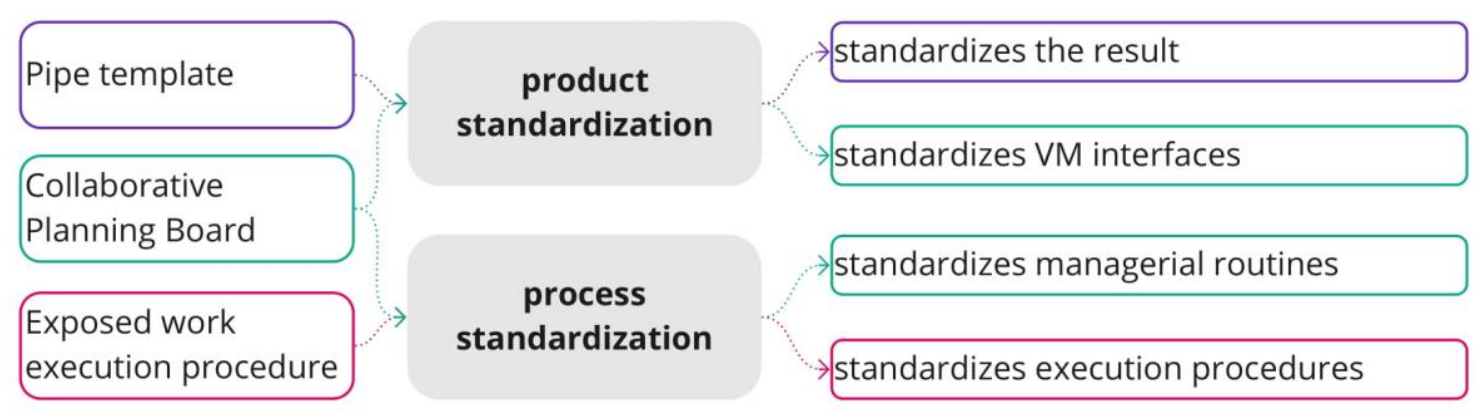

Figure 5: Different meanings of "standardization" according to the VM practice. 
Comparing the main purpose of using the collaborative planning board in relation to using the pipe template, it is possible to note the latter is focused on generating adherence to the design. The activity in the field has to occur according to some established specifications. On the other hand, the former is based on the idea of changing or at least adapting, a previously established plan based on the shared understanding about the milestones among all participants.

For Koskela (2015), one of the challenges in construction management is to make people in the field adhere to the plan. That author argues that visual management could be regarded as a rhetorical strategy for making it possible, as it simplifies the information, improving shared understanding. Standards are important for making deviations clear and can be an important source for continuous improvement (Spear and Bowen 1999). Management based on the lean production philosophy means letting some room for learning, and opportunities for people to question and suggest changes. Process transparency also plays a key role in supporting learning. This study indicated that shared understanding can be obtained in different manners, such as in practices that support adherence to standards, such as in the pipe template practice, or by using collaboration to discuss and refine decisions, such as in the case of the collaborative planning board practice.

\section{CONCLUSIONS}

This investigation presents the results of an ongoing research project which aims to develop a serious game to teach VM as well as to improve the understanding of this topic. The proposed conceptual map of the relationships between VM purposes is one of the analyses that was undertaken. Perceptions of different stakeholders were used to define a set of purposes for the three practices. Then through a group discussion, the purposes were organized according to their connections, which was not explored in the existing literature.

These are the main findings so far: (i) many VM purposes are strongly related to each other, so it is useful to organize them in a conceptual map; (ii) some purposes are more specific, more objective, and related directly to the current practice, while others are more generic and abstract; (iii) one specific purpose can have different meanings in each practice, so context analysis is fundamental for purpose understanding; and (iv) shared understanding can be achieved differently, such as by adherence or by collaboration.

The analyses presented in this paper were limited to three VM practices. Future work should explore many other practices, encouraging a further reflection about the theoretical and practical understanding of VM aspects. As mentioned before, the discussion about VM purposes is only one step in the serious game, which is under development. Further studies will explore conceptual models related to other VM elements, such as context understanding, requirements, and the roles of communication and collaboration. It is expected that this body of knowledge will contribute to understanding the VM in a broader way and its use in construction projects.

\section{ACKNOWLEDGEMENTS}

The authors thank the Coordination for the Improvement of Higher Education Personnel (CAPES) for the financial support received. The authors are also grateful to the participants involved in the workshops, as well as Arcadis and the other companies for supporting the development of this investigation. 


\section{REFERENCES}

Van Aken, J. E. (2004). "Management research on the basis of the design paradigm: The quest for field-tested and grounded technological rules." Journal of Management Studies, 41(2), 219-246.

Ballard, G., and Howell, G. (1998). "Shielding Production: Essential Step in Production Control." Journal of Construction Engineering and Management, 124, 11-17.

Bernstein, E. S. (2012). "The Transparency Paradox: A Role for Privacy in Organizational Learning and Operational Control." Administrative Science Quarterly, Sage Publications, 57(2), 181-216.

Brady, D. A., Tzortzopoulos, P., Rooke, J. A., Formoso, C. T., and Tezel, A. (2018). "Improving transparency in construction management: a visual planning and control model." Engineering, Construction and Architectural Management, (August), ECAM-07-2017-0122.

Clarke, A., and Dawson, R. (1999). Evaluation Research. International Encyclopedia of Education, SAGE Publications Ltd, 6 Bonhill Street, London England EC2A 4PU United Kingdom.

Dallasega, P., Rauch, E., and Linder, C. (2018). "Industry 4.0 as an enabler of proximity for construction supply chains: A systematic literature review." Computers in Industry, Elsevier, 99(August 2017), 205-225.

Eaidgah, Y., Maki, T. A. A., Kurczewski, K., and Abdekhodaee, A. (2016). "Visual management, performance management and continuous improvement: a lean manufacturing approach." International Journal of Lean Six Sigma, 7(2).

Ewenstein, B., and Whyte, J. K. (2007). "Visual representations as 'artefacts of knowing." Building Research and Information, 35(1), 81-89.

Formoso, C. T., dos Santos, A., and Powell, J. A. (2002). "An exploratory study on the applicability of process transparency in construction sites." Journal of Construction Research, 3(1), 35-54.

Galsworth, G. (1997). Visual systems: harnessing the power of the visual workplace. American Management Association, New York.

Greif, M. (1991). The visual factory: building participation through shared information. CRC Press, Portland.

Gunasekaran, A., Goyal, S. K., and Martikainen, T. (1998). "Total Quality Management : A New Perspective for Improving Quality and Productivity." International Journal of Quality \& Reliability Management, 15(8), 947-968.

Hirano, H. (1995). 5 Pillars of the Visual Workplace: The Sourcebook for $5 S$ Implementation. Productivity Press, New York.

Holmström, J., Ketokivi, M., and Hameri, A.-P. (2009). "Bridging Practice and Theory: A Design Science Approach." Decision Sciences, 40(1), 65-87.

Howell, G., and Ballard, G. (1999). "Design of Construction Operations." 1-9.

Klotz, L., Horman, M., Bi, H. H., and Bechtel, J. (2008). "The impact of process mapping on transparency." International Journal of Productivity and Performance Management, 57(8), 623-636.

Koskela, L. (1992). "Application of the New Production Philosophy to Construction." Center for Integrated Facility Engineering, Stanford University, Stanford.

Koskela, L. (2000). "An exploration towards a production theory and its application to construction.” VTT Building Technology, (L. Ukskoski, ed.), Technical Research Centre of Finland, Espoo, Finland, Finland. 
Koskela, L. (2015). "Where Rhetoric and Lean Meet." 23rd Annual Conference of the International Group for Lean Construction, O. Seppänen, V. A. González, and P. Arroyo, eds., Perth, Australia, 527-535.

Koskela, L., Tezel, A., and Tzortzopoulos, P. (2018). "Why Visual Management?" 26th Annual Conference of the International Group for Lean Construction, Chennai, India, 250-260.

Lindlöf, L. (2014). Visual Management - on Communication in Product Development Organizations Department of Technology Management and Economics. Chalmers Reproservice, Gothenburg, Sweden.

Lukka, K. (2003). "The Constructive Research Approach." Case study research in logistics, Series B, 83-101.

Mejabi, O. O. (2003). "Framework for a lean manufacturing planning system." International Journal of Manufacturing Technology and Management, 5(5-6), 563578.

Nicolini, D. (2007). "Studying visual practices in construction." Building Research and Information, 35(5), 576-580.

Tezel, A. (2011). "Visual management: an exploration of the concept and its implementation in construction." University of Salford.

Tezel, A., and Aziz, Z. (2017). "From Conventional to IT Based Visual Management: A Conceptual Discussion for Lean Construction." Journal of Information Technology in Construction, 22, 220-246.

Tezel, A., Koskela, L., and Aziz, Z. (2018). "Lean thinking in the highways construction sector: motivation, implementation and barriers." Production Planning and Control, Taylor \& Francis, 29(3), 247-269.

Tezel, A., Koskela, L., and Tzortzopoulos, P. (2009). "The functions of visual management." International Research Symposium, 201-219.

Tezel, A., Koskela, L., and Tzortzopoulos, P. (2016). "Visual management in production management: a literature synthesis." Journal of Manufacturing Technology Management, 27(6), 766-799.

Valente, C. P., Brandalise, F. M. P., and Formoso, C. T. (2019). "Model for Devising Visual Management Systems on Construction Sites." Journal of Construction Engineering and Management, 145(2), 04018138-1 04018138-17.

Viana, D. D., Formoso, C. T., Wesz, J., and Tzortzopoulos, P. (2014). "The role of visual management in collaborative integrated planning and control for engineer-to-order building systems." 22nd Annual Conference of the International Group for Lean Construction, Oslo, Norway, 775-786. 